\title{
Effects of uncertainty and quasi-chaotic geometry on the leakage of brush seals
}

\author{
Alexander Fuchs ${ }^{1 *}$, Oskar J. Haidn ${ }^{1}$

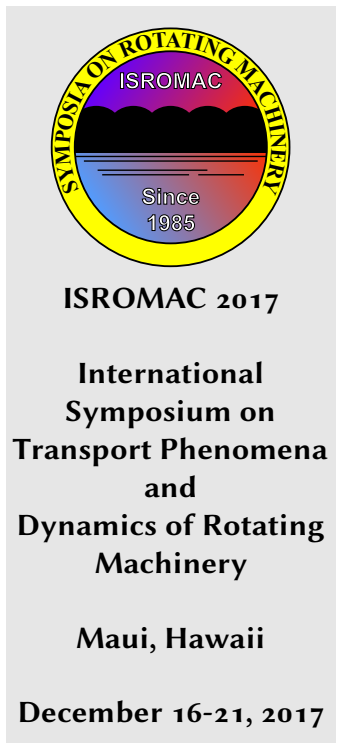

\begin{abstract}
This paper presents a brief review of the experimental and theoretical state of the art regarding the leakage flow prediction of brush seals. The authors model a computational fluid dynamics based approach for the leakage flow of brush seals. The brush seal is treated by its real geometrical structure, namely numerous bristles in an array in transverse flow. For the inner composition of the package, two differing textures are chosen to study their influence on the leakage behavior. Furthermore, for each texture multiple inter-bristle distances, pressure ratios and turbulence models are evaluated. In addition, the influence of not regular arrangement configurations, which form a quasi-chaotic inner structure, are studied. The gained results are compared to other authors' experimental and numerical data.
\end{abstract} \\ Keywords \\ Brush seal - Leakage - Quasi-chaotic - CFD \\ 'Division Space Propulsion, Chair of Turbomachinery and Flight Propulsion, Department of Mechanical Engineering, Technical \\ University of Munich (TUM), Munich, Germany \\ *Corresponding author: alexander.fuchs@ltf.mw.tum.de
}

NOMENCLATURE

\begin{tabular}{|c|c|}
\hline \multicolumn{2}{|c|}{ Abbreviations } \\
\hline$G C I$ & Grid convergence index \\
\hline CAD & Computer aided design \\
\hline CFD & Computational fluid dynamics \\
\hline $\mathrm{DM}$ & ANSYS $^{\circledR}$ DesignModler $^{\mathrm{TM}}$ \\
\hline Fluent & ANSYS $^{\circledast}$ Fluent $^{\circledast}$ \\
\hline ICEM & ANSYS $^{\circledast}$ ICEM CFD $^{\text {TM }}$ \\
\hline JS & JavaScript $^{\mathrm{TM}}$ \\
\hline MTU & Motoren- und Turbinenunion \\
\hline $\mathrm{Q}_{2} \mathrm{D}$ & Quasi two dimensional \\
\hline \multicolumn{2}{|c|}{ Dimensionless numbers } \\
\hline$R e$ & Reynolds number \\
\hline$y^{+}$ & Dimensionless wall distance \\
\hline \multicolumn{2}{|l|}{ Greek } \\
\hline$\delta$ & Inter bristle distance \\
\hline$\epsilon$ & Turbulent dissipation \\
\hline$\mu$ & Expected value \\
\hline$\omega$ & Specific turbulent dissipation \\
\hline$\phi$ & Variable of interest in $G C I$ \\
\hline$\Pi$ & Pressure ratio $=p_{u s} / p_{d s}$ \\
\hline$\sigma^{2}$ & Variance \\
\hline
\end{tabular}

\begin{tabular}{ll}
$\Delta p$ & Pressure differential \\
$\dot{m}$ & Leakage mass flow rate \\
$B$ & Effective thickness \\
$d$ & Bristle diameter \\
$e$ & Error \\
$I$ & Turbulent intensity \\
$k$ & Turbulent kinetic energy \\
$L$ & Length \\
$N$ & Number of rows \\
$P$ & Probability density function \\
$p$ & Pressure \\
$u$ & Velocity \\
$x$ & Position \\
Subscripts \\
$a$ & Axial \\
$c$ & Circumferential \\
$d s$ & Downstream \\
$e f f$ & effective \\
$h$ & Hexagon \\
$i$ & Axis direction \\
$r$ & Radial \\
$r e l$ & relative \\
$s$ & Square \\
$s t a t$ & Static \\
tot & Total \\
$u s$ & Upstream \\
& \\
\hline &
\end{tabular}




\section{INTRODUCTION}

To accomplish the goal of improving the overall efficiency of thermal turbomachinery, the development and improvement of the secondary flow system of this machinery is a crucial task. Using advanced sealing technologies for this demanding task, has been shown to be very beneficial [1]. Brush seals are one of these advanced seals.

To lay the foundation for a deeper understanding of brush seals, a bottom-up strategy gaining an empirically validated numerical fluid-structure interaction model is required. The first cornerstone of this strategy - generating a sub-system flow model of the bristle package - is to be accomplished by creating a parameterized computational fluid dynamic model and analyzing the flow through the bristle package without its movement. Validating this model, results from different sources are used and briefly discussed.

\section{System description}

Figure 1 shows a brush seal in MTU Aero Engines design [2]. In the cross sectional view (figure 1 (a)) the main components of this sealing type can be seen, containing sealing element (consisting of the bristle pack, central wire and c-tube) and housing. To reduce and protect the sealing element from flow distortions of the upstream flow, the outer part of the housing - the cover ring - is used. Downstream of the bristle pack the support ring is installed to support the sealing element from bending due to the pressure differential $\Delta p$ across the sealing. Both rings combined act as housing of the brush seal and clamp the sealing element inside them. The main part of this sealing is the sealing element between the both rings. It consists of a vast number of individual bristles and a clamping device (figure 1 (b)). The main difference between the shown and other manufacture designs is the fixation of the bristles. While these are commonly welded together, the MTU Aero Engines design uses a cut open tube, called c-tube due to its shape, and a wire where the bristles are laying around of. The c-tube is clamped over the upper part of the sealing element, thus locks the bristles from moving. Due to the support rings' geometrical shape, the radial outer part of the support ring does not touch the bristle pack. Therefore, in the arising cavity, the pressure relief chamber, the pressure $p$ adapts to the upstream pressure $p_{u s}$. This effect is intended to generate a counter acting force on the bristle pack which adapts automatically to the pressure differential $\Delta p$ and therefore reduces the bristles deformation.

Because of the great number of individual wires, which deform reversibly under the attack of external forces, this sealing type is challenging to build, apply, and even more to model due to the interaction of the flow and and the bristle package.

\section{Experimental work from other authors}

Several studies regarding the leakage flow behaviour of brush seals have been carried out experimentally. Bayley and Long [3] have measured the leakage on a static (no shaft rotation)

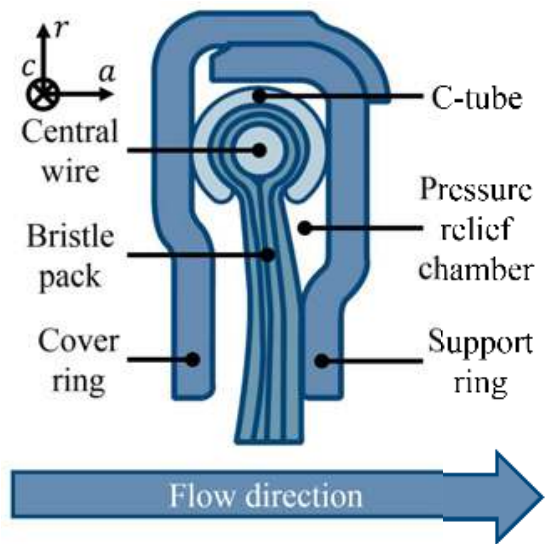

(a) Cross section of a brush seal.

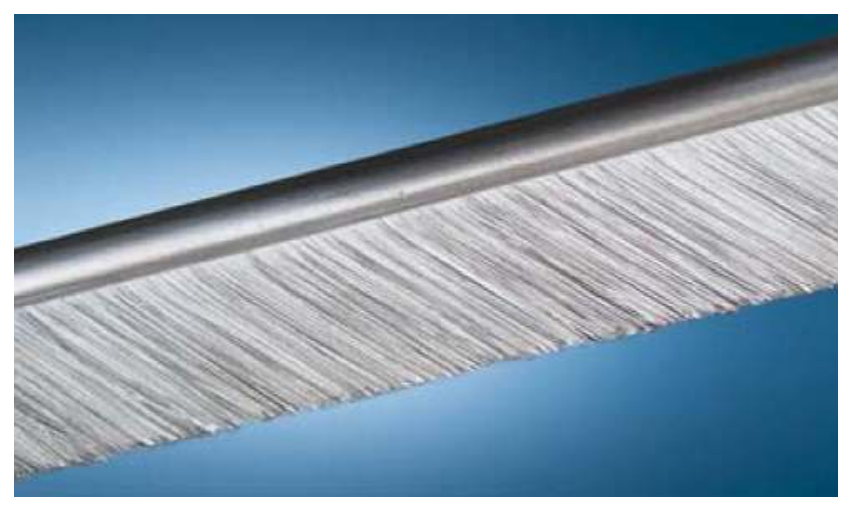

(b) Axial view of bristle pack without housing.

Figure 1. Brush seal in MTU Aero Engines design [2].

test bench. O'Neill et al. [4] has researched the influence of multiple brush seals in a row, while Carlilie et al. [5] have generalized the results regarding brush seals in operation for several different fluids. Braun et al. [6-8] have carried out flow visualization experiments where some interesting flow phenomena such as jetting, rivering, lateral, wall and vortical flow were observed. Furthermore Braun et al. [6-8] have shown that the bristle configuration intensively affect not only the flow phenomena but also the pressure drop across the brush seal.

\section{Theoretical work from other authors}

Multiple approaches have been applied to determine the leakage mass flow across a brush seal, differing in the treatment of the bristle pack and the way the computational work is performed. Braun et al. [6,7] and Hendricks et al. $[9,10]$ used analytical bulk flow models which treat the bristle pack as a porous medium. These models are related to experimental results to compute the leakage mass flow. Bulk flow models have the main disadvantage to be not capable of predicting the pressure distribution inside the bristle pack but are fairly accurate in close range with respect to the experimental basis. To extend the valid range, Chupp et al. [11] generalized the results over a wider range of conditions implementing the effective thickness $B_{e f f}$ of a brush seal introduced in a pre- 
vious work of Dowler et al. [12]. To overcome the drawback of missing the pressure distribution within the bristle pack, porous media models with a differing theoretical basis were developed. Bayley and Long [3] used an analytical porous media approach where they solved Laplace's equations. Chew et al. [13] states, this approach is equivalent of treating the bristle pack as an anisotropic Darcian porous medium.

With increasing computational capacity the numerical investigation of brush seals has become a promising approach. Chew et al. $[13,14]$ have implemented a porous media approach based on an anisotropic Darcian medium in a two dimensional axis-symmetric CFD model. To solve the porous media region properly, source terms in the momentum equations are introduced. This methodology was used and refined by many authors. Pröstler $[15,16]$ has considered a three dimensional CFD model, Dogu et al. [17-21] has researched the influence of geometry variations, Chen et al. $[22,23]$ and Flouros et al. $[24,25]$ have used the resulting pressure distribution to predict bristle pack deformation, Qiu et al. [26, 27] and Li et al. [28-30] studied the heat generation due to frictional forces on the rotor, and Helm et al. [31] has simulated a test bench including labyrinth and brush seals.

Beside porous media models, approaches have been applied which treat the bristle pack as an array of cylinders in transverse flow. Braun et al. [32,33] discretize the cylinders in a rather rough manner, being refined later on by Kudriavtsev and Braun [34]. Hendricks et al. [35] and Sharatchandra and Rhode $[36,37]$ have computed only a partial region between the bristles and have applied periodic boundary conditions to get results of the entire bristle pack. Lelli et al. [38, 39], Pekris et al. [40-42], and Sun et al. [43] have coupled their CFD results to a computational structural mechanics tool to distinguish the deformation of the bristle pack. Furthermore, Chew and Guardino [44] and Huang et al. [45] have investigated the frictional heat due to friction with the rotors' surface.

\section{Objectives of this paper}

In this paper a CFD based model is presented which is based on modeling an array of bristles in transverse flow. The influence of the inter-bristle distance $\delta$, pressure ratio $\Pi$, multiple turbulence models and inner bristle composition are evaluated and tested against other authors' results. In addition, the effects of quasi-chaotic arrangement within the bristle pack are investigated.

\section{METHODOLOGY}

\subsection{Geometrical structure and modeling}

The geometrical structure is gained by a MATLAB ${ }^{\circledR}$ tool which has been developed for this purpose. This tool allows to configure the number of axial $\left(N_{a}\right)$ and quasi-circumferential $\left(N_{c}\right)$ bristle rows, the diameter $d$ of the bristles and their distance $\delta$ among each other. Furthermore, the shape of the circumscribing area of a bristle can be defined. Due to geometrical limitations (exclusively triangles, squares and hexagons are space-filling in $2 \mathrm{D}$ euclidean space) only squares and hexagons are implemented. This leads to two differing inner bristle pack compositions (see figure 2).

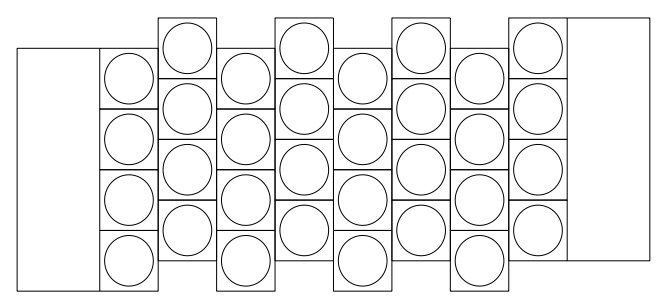

(a) Square shaped bristle surrounding.

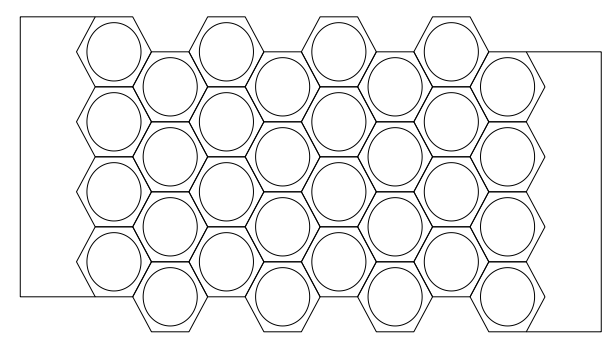

(b) Hexagonal shaped bristle surrounding.

Figure 2. Exemplary regular bristle pack arrangements in a $a-c$-cross-section.

One of the most notable distinctions is that the hexagonal shaped structure, besides its representation of the most compact packing possible, allows back tapering of the bristles, while the square shaped inner structure does not. Also the hexagonal shaped circumscription is the usually assumed inner composition of a brush seal [12], the square shaped surrounding in contrast leads to significantly simpler numerical meshes. Therefore, a comparison between both is carried out.

In addition, a probability density function $P_{i}$ regarding the axial and circumferential position of the center point of each individual bristle can be applied within their circumscribing area. In this study a normal distribution is used (equation 1 ) as probability density function $P_{i}$. As expected value $\mu$ the center point position of the regular arrangement is set.

$$
P_{i}=\frac{1}{\sqrt{2 \pi \sigma^{2}}} e^{-\frac{\left(x_{i}-\mu\right)^{2}}{2 \sigma^{2}}}
$$

Depending on the variance $\sigma^{2}$ the geometrical structure can be altered from a regular arrangement with $\sigma^{2}=0$ (figure 3 (a) and (c)) to a quasi-chaotic arrangement with $\sigma^{2}>0$ (figure 3 (b) and (d)). The resulting displacement is limited so, that all bristles stay within their circumscribing area. Therefore, a limiting curve can be defined which must not be passed by the center points. This curve is a smaller concentric 


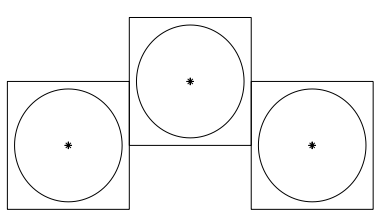

(a) Square shaped without displacement.

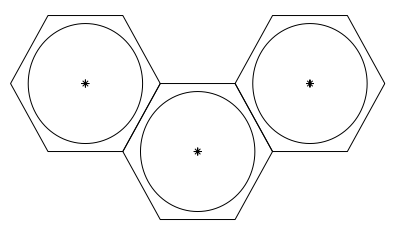

(c) Hexagonal shaped without displacement.

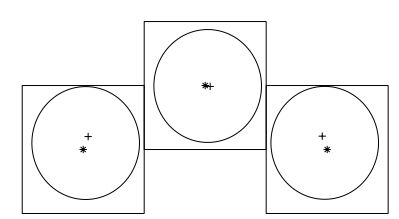

(b) Square shaped including displacement.

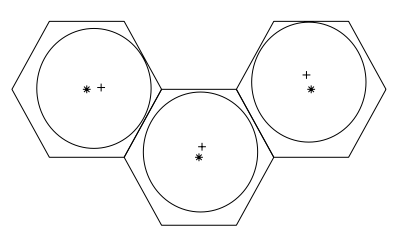

(d) Hexagonal shaped including displacement.
Figure 3. Exemplary inner bristle pack compositions without and including displacement.

circle related to the in-circle of the considered surrounding structure. Due to numerical limitations, the maximal displacement is set to be slightly smaller than the mentioned limiting curve. Figure 4 represents an exemplary distribution of the center points of individual bristles which leads to a quasi-chaotic arrangement. Furthermore, the first and last row in circumferential direction $c$ are set to feature the same deviation vector to ensure that the periodic boundary conditions set later on perform well. By enlarging the variance $\sigma^{2}$, the quasi-chaotic behaviour of the inner composition of the bristle pack increases. If variances $\sigma^{2}$ are chosen which tend to generate most of the center points beyond the limiting curve, the inner composition of a bristle pack reaches a frozen state regarding the average displacement.

Furthermore, the tool allows to vary the inlet and outlet path length easily be varying input parameters. In table 1 geometry and model parameters are listed. The final output

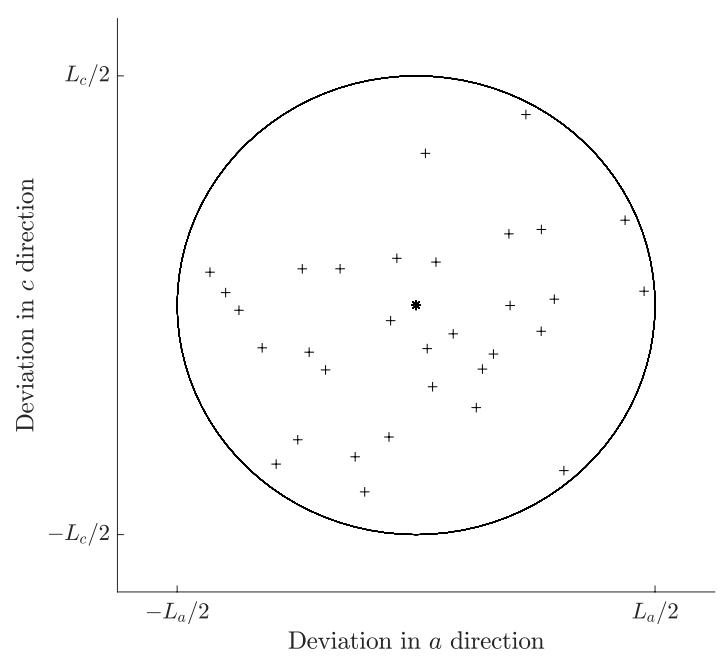

Figure 4. Exemplary center point distribution and limiting curve of a quasi-chaotic arrangement. of the tool is a JavaScript ${ }^{\mathrm{TM}}$ with ANSYS $^{\circledR}$ DesignModler $^{\mathrm{TM}}$ commands. This JS is processed within DM to gain a $3 \mathrm{D}$ computer aided design model.

Table 1. Geometry and model parameters

\begin{tabular}{lccc}
\hline Parameter & Symbol & Value & Unit \\
\hline Bristle diameter & $d$ & $1.5 \times 10^{-4}$ & $m$ \\
Inter bristle distance & $\delta$ & $7-9 \times 10^{-5}$ & $m$ \\
Number of axial rows & $N_{a}$ & 8 & - \\
$\begin{array}{l}\text { Number of } \\
\text { circumferential rows }\end{array}$ & $N_{c}$ & $1-4$ & - \\
$\begin{array}{l}\text { Variance } \\
\begin{array}{l}\text { Upstream total } \\
\text { pressure }\end{array}\end{array}$ & $\sigma^{2}$ & $1-2 \times 10^{-12}$ & - \\
$\begin{array}{l}\text { Downstream static } \\
\text { pressure }\end{array}$ & $p_{u s}$ & $1.5-9$ & bar \\
\hline
\end{tabular}

\subsection{Meshing and grid convergence study}

Using ANSYS $^{\circledR}$ Workbench $^{\mathrm{TM}}$ the $3 \mathrm{D}$ CAD model is interconnected with ANSYS ${ }^{\circledR}$ ICEM CFD $^{\text {TM }}$ where, based on user generated templates, a structured multi-block mesh is generated automatically for both surrounding types (see figure 5). All grids considered in this study represent quasi two dimensional domains, with only one cell in radial direction of the brush seal. Furthermore, all generated meshes satisfy

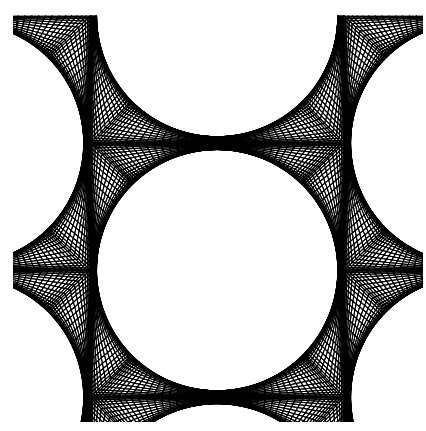

(a) Square shaped circumscription.

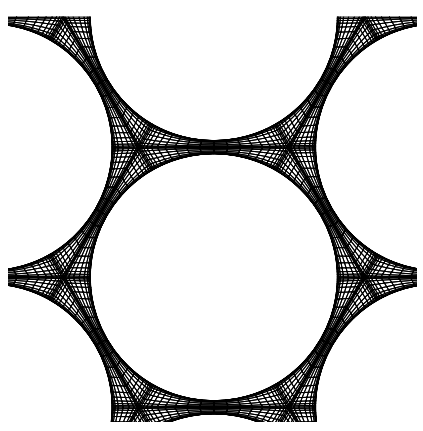

(b) Hexagonal shaped circumscription.
Figure 5. Details of exemplary numerical meshes for both considered arrangements.

the numerical requirement of $y^{+} \leq 1$ to resolve the viscous sublayer on the bristle surfaces. A grid convergence study is carried out applying the grid convergence index [46]. As the variable of interest $\phi$ the leakage mass flow rate $\dot{m}$ of the bristle pack is defined. For both bristle surrounding types a geometrical setup without displacement and a pressure ratio of $\Pi=8.90$ is used. As table 2 clearly states for both meshes the finest refinement leads to an acceptable $G C I$. Based on this results for both surrounding types the finest mesh with 128000 cells and 85724 cells respectively are used for further investigations. 
Table 2. Results of the grid convergence study with the grid convergence index [46]. For all results presented in this table the Transition-SST model [47] for turbulence modeling, a pressure ratio $\Pi=8.90$, and $N_{c}=4$ are used.

\begin{tabular}{|c|c|c|c|}
\hline \multicolumn{4}{|c|}{ Square shaped bristle surrounding } \\
\hline & Coarse & Middle & Fine \\
\hline Cells $[-]$ & 71680 & 99840 & 128000 \\
\hline$h\left[10^{-6} \mathrm{~m}\right]$ & 7.03 & 6.02 & 5.41 \\
\hline$r[-]$ & \multicolumn{2}{|l|}{1.17} & 1.11 \\
\hline$\phi=\dot{m}\left[10^{-7} \frac{\mathrm{kg}}{\mathrm{s}}\right]$ & \multirow[t]{2}{*}{4.55} & 4.58 & \multirow[t]{2}{*}{4.58} \\
\hline$p[-]$ & & 30.5 & \\
\hline$\phi_{\text {ext }}\left[10^{-7} \frac{\mathrm{kg}}{\mathrm{s}}\right]$ & \multicolumn{2}{|l|}{4.78} & 4.57 \\
\hline$e_{a}[\%]$ & \multicolumn{2}{|l|}{0.74} & 0.03 \\
\hline$e_{\text {ext }}[\%]$ & \multicolumn{2}{|l|}{4.23} & 0.25 \\
\hline$G C I[\%]$ & \multicolumn{2}{|l|}{5.30} & 0.29 \\
\hline \multicolumn{4}{|c|}{ Hexagonal shaped bristle surrounding } \\
\hline & Coarse & Middle & Fine \\
\hline Cells $[-]$ & 41800 & 60800 & 85724 \\
\hline$h\left[10^{-6} \mathrm{~m}\right]$ & 6.78 & 5.91 & 5.26 \\
\hline$r[-]$ & \multicolumn{2}{|l|}{1.15} & 1.12 \\
\hline$\phi=\dot{m}\left[10^{-7} \frac{\mathrm{kg}}{\mathrm{s}}\right]$ & \multirow[t]{2}{*}{4.78} & 4.69 & \multirow[t]{2}{*}{4.71} \\
\hline$p[-]$ & & 14.1 & \\
\hline$\phi_{\text {ext }}\left[10^{-7} \frac{\mathrm{kg}}{\mathrm{s}}\right]$ & 4.12 & & 4.84 \\
\hline$e_{a}[\%]$ & 1.81 & & 0.35 \\
\hline$e_{\text {ext }}[\%]$ & 13.93 & & 2.73 \\
\hline$G C I[\%]$ & 14.67 & & 3.36 \\
\hline
\end{tabular}

\subsection{Solving the governing equations and do- main settings}

For the purpose of solving the governing flow field equations the commercial CFD solver ANSYS ${ }^{\circledR}$ Fluent $^{\circledR}$ is used. Turbulence is modeled by Reynolds averaged Navier-Stokes equations, using two ( $k-\epsilon$ RNG [48] and $k-\omega$ SST with lowReynolds correction [49]) and four equation (TransitionSST [47]) turbulence models.

Due to the $\mathrm{Q}_{2} \mathrm{D}$ domain setup, boundary conditions are applied on all boundary faces. The inlet face is considered as a pressure inlet where the inlet total pressure $p_{\text {tot }}$ is set to multiple pressure levels within this study. For the outlet face a pressure outlet boundary condition with a constant static pressure of $p_{\text {stat }}=1.0 \mathrm{bar}$ is set. For both faces in circumferential domain direction transitional matching periodic boundary conditions, in radial dimension symmetry boundary conditions are used. Therefore, the domain setting represents a section of a linear brush seal element underneath the support ring. Furthermore, as fluid dry air is used and modeled as an ideal gas.

\section{RESULTS}

In this study multiple parameters are varied and their influence on the leakage mass flow rate $\dot{m}$ is investigated. Valida- tion of the results is a demanding task, since only limited data is available for this purpose. Experimental data regarding the flow characteristics typically only provide the upstream and downstream pressure as well as the resulting leakage mass flow rate $\dot{m}$. Usually no statements are made relating to the geometrical inner composition, movement and resulting displacement, or the pressure and velocity field within the bristle pack. Theoretical data from other authors' are based on and calibrated with these experimental results. Therefore, for a validation purpose only the resulting leakage mass flow rate $\dot{m}$ for a given pressure ratio $\Pi$ can be used.

An initial study investigated the influence of the considered number of bristle rows $N_{c}$ in circumferential direction $c$. No impact could be observed by variation of $1<N_{c}<4$. For all further simulations $N_{c}=4$ was chosen to lay the foundation for the investigation of quasi-chaotic displacement, where a minimum number of rows in circumferential direction $c$ is essential to provide a sufficiently large domain.

\subsection{Influence of inter-bristle distance $\delta$ and shape of circumscribing area}

The inter-bristle distance $\delta$ is defined as distance between two bristles in circumferential direction $c$. Depending on the considered surrounding type, the distances between bristles in other directions than circumferential in the $a$-c-plane is controlled by the geometrical composition. Due to the fact that the main pressure gradient acts in axial direction, the inter-bristle distance $\delta$ defines, for both considered circumscribing shapes, the narrowest gap transverse to the flow direction. Therefore, the inter-bristle distance $\delta$ influences the resulting leakage mass flow rate $\dot{m}$ intensely (see figure 6). The deviation of the leakage mass flow rate $\dot{m}$ related

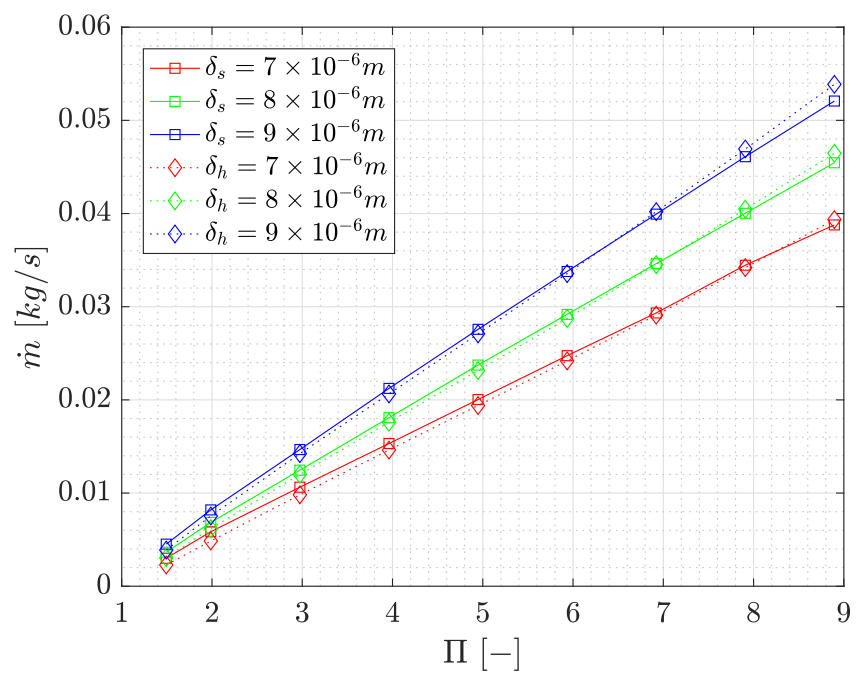

Figure 6. Influence of inter-bristle distance $\delta$ and shape of circumscribing area. For all results shown in this figure the Transition-SST model [47] for turbulence modeling and $N_{c}=4$ are used.

to the resulting leakage mass flow rate $\dot{m}$ of a inter-bristle distance of $\delta=8 \times 10^{-6}$ reach from $15 \%$ up to $30 \%$. Further- 
more, figure 6 shows the influence of the bristle surrounding shape. Square shaped surroundings result in a higher leakage mass flow rate $\dot{m}$ for low pressure ratios $\Pi$. With increasing pressure ratios $\Pi$ the simulated leakage mass flow rates for both surrounding types converge to one another, until they intersect. After this intersection, the simulations with hexagonal shaped circumscribing area show higher leakage mass flow rates $\dot{m}$. In addition, the point of intersection of both leakage mass flow rate trends shifts to lower pressure ratios $\Pi$ with increasing inter-bristle distance $\delta$.

Figure 7 shows the numerical results of this study correlated against the results of Bayley and Long [3], Chew et al. [13], Flouros et al. [24, 25], and experimental data from MTU Aero Engines. Due to the fact that the results from

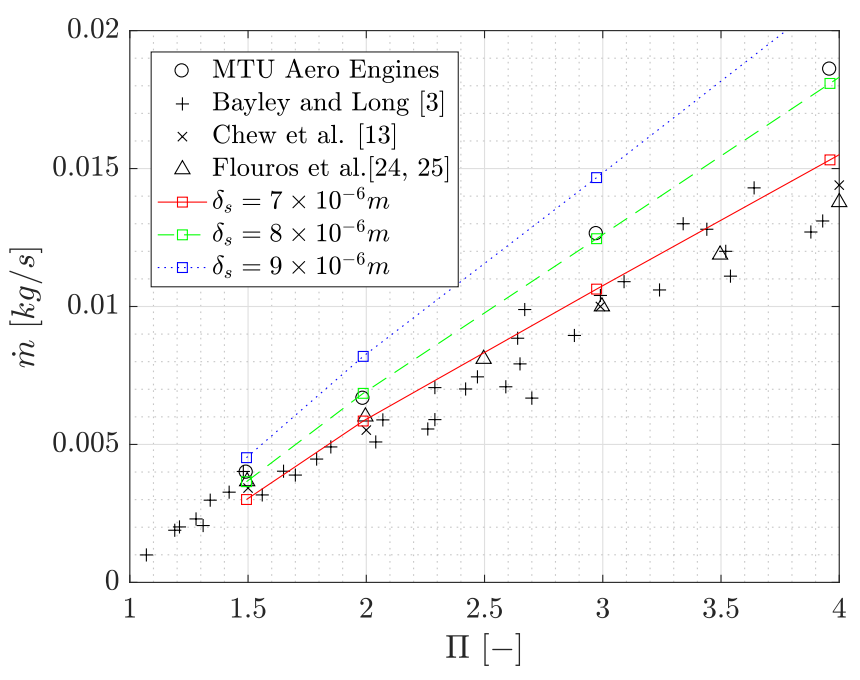

(a) Square shaped bristle surrounding.

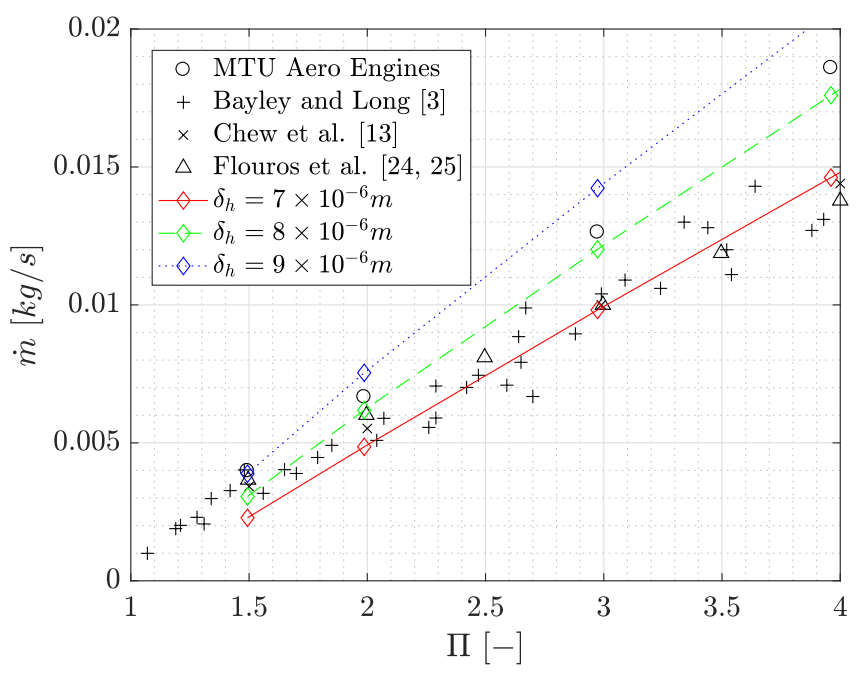

(b) Hexagonal shaped bristle surrounding.

Figure 7. Correlation of the numerical results of this study against experimental and theoretical findings from other authors. For all results shown in this figure the Transition-SST model [47] for turbulence modeling and $N_{c}=4$ are used. the literature are only available in a range of $1<\Pi<4$, only this detail is shown here and considered for validation. Generally, the presented results correlate qualitatively well with data from the literature. The leakage mass flow rate $\dot{m}$ shows the supposed linear dependency relating to the pressure ratio $\Pi$ for both investigated bristle surrounding types and the same order of magnitude. For a quantitative comparison of the results it has to be noted, that only the experimental data from MTU Aero Engines features the same bristle diameter of $d=1.5 \times 10^{-4} \mathrm{~m}$ like in the performed numerical simulations of this study. The results of Bayley and Long [3] are based on measurements of a brush seal with a bristle diameter of $d=7.622 \times 10^{-5} \mathrm{~m}$. Chew et al. [13] and Flouros et al. $[24,25]$ calibrated their porous media approach based simulations on the experimental findings of Bayley and Long [3]. Considering this fact, the numerical results for both investigated surrounding types with a inter-bristle distance of $\delta=8 \times 10^{-6} \mathrm{~m}$ show the best agreement with the reference data from MTU Aero Engines. Therefore, all further mentioned results use an inter-bristle distance of $\delta=8 \times 10^{-6} \mathrm{~m}$ as their basis.

\subsection{Influence of turbulence modeling}

Initial simulations showed a significant turbulent intensity $I$ within the bristle pack. Therefore, the influence of turbulence modeling on the flow field and especially on the resulting leakage mass flow rate $\dot{m}$ of the simulated bristle pack has been investigated in this study. Three widely used turbulence models are tested against each other. The first two turbulence models are two equation models; the $k-\epsilon$ RNG model [48] and the $k-\omega$ SST model with low-Reynolds correction [49]. The third turbulence model is the four equation Transition-SST model [47]. Figure 8 shows the results for both bristle surrounding types and all considered turbulence models. Generally, all three models show very similar results. The $k-\epsilon$ RNG model performs better for square shaped bristle surroundings than for hexagonal ones, even better than the $k-\omega$ SST model for the square shaped circumscription. For both bristle surrounding types the Transition-SST model correlates best with the experimental data. In case of the hexagonal surrounding the $k-\omega$ SST model leads to almost identical results than the Transition-SST model. Table 3 shows the relative errors $e_{r e l}$ of all considered turbulence models related to the experimental data from MTU Aero Engines. Based on this results for all further simulations the Transition-SST model is chosen.

\subsection{Influence of quasi-chaotic displacement}

For the investigation on the influence of quasi-chaotic displacement of each individual bristle on the leakage mass flow rate $\dot{m}$ the method described in section 1.1 is used. Therefore, in both surrounding types a probability density function $P_{i}$ (see equation 1) is applied and the variance $\sigma^{2}$ is varied. In figure 9 the results of this analysis are shown. The square shaped circumscribing area as well as the hexagonal shaped one show the same trend towards a decline in the leakage mass flow rate $\dot{m}$ with increasing variance $\sigma^{2}$ relating to 


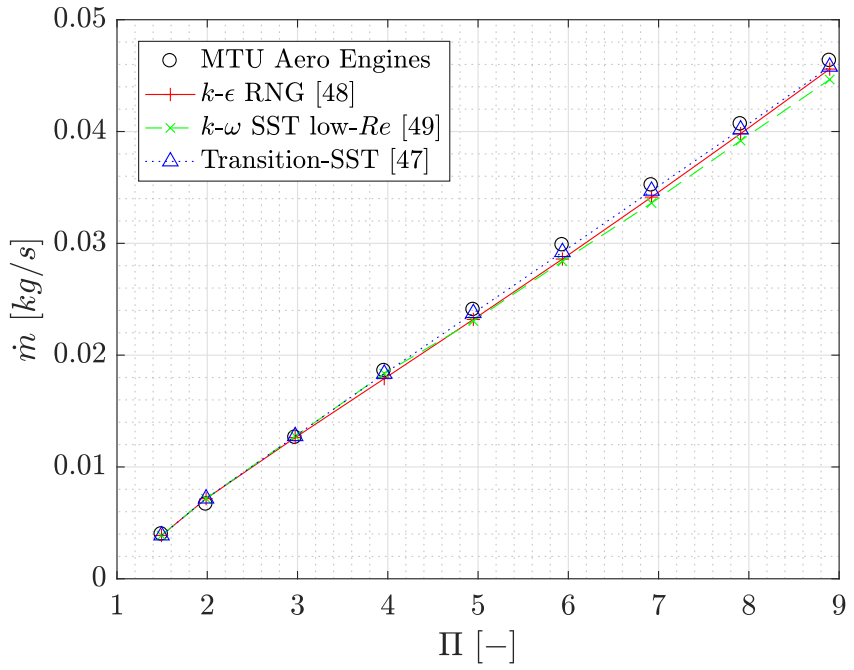

(a) Square shaped bristle surrounding.

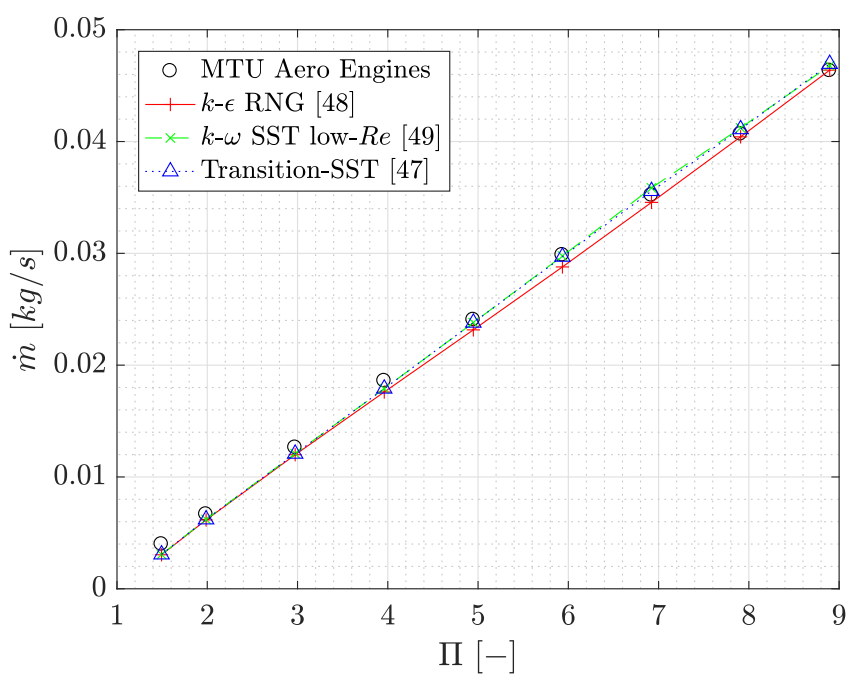

(b) Hexagonal shaped bristle surrounding.

Figure 8. Comparison of different turbulent models. For all results shown in this figure a inter-bristle distance of $\delta=8 \times 10^{-6} \mathrm{~m}$ and $N_{c}=4$ are used.

the results for regular arrangement with $\sigma^{2}=0$. Multiple simulations with the same variance $\sigma^{2}$ but differing in the resulting geometrical displacement, due to the quasi-chaotic methodology, were performed. This analysis indicates that for equally chosen variance values the resulting leakage mass flow rate $\dot{m}$ stays almost identical. Therefore, it can be concluded that only the order of deviation due to the variance $\sigma^{2}$ plays a role. The resulting deviated geometrical composition only acts on a minor scale. Nevertheless the decrease of the leakage mass flow rate $\dot{m}$ is verifiable, the quasi-chaotic displacement only has a minor impact on the overall results. As can be seen in table 4 , the deviation of the leakage mass flow rate $\dot{m}$ lies within the error margin of the simulation (see table 2).

Although the influence on the leakage mass flow rate $\dot{m}$ of a quasi-chaotic displacement of the inner bristle composition
Table 3. Relative error $e_{\text {rel }}$ of leakage mass flow rate $\dot{m}$ of turbulence models relating to experimental data from MTU Aero Engines.

\begin{tabular}{lccc}
\hline \multicolumn{4}{c}{ Square shaped bristle surrounding } \\
$\begin{array}{l}\text { Turbulence } \\
\text { model }\end{array}$ & $e_{\text {rel,min }}[\%]$ & $e_{\text {rel,max }}[\%]$ & $\overline{e_{\text {rel }}}[\%]$ \\
\hline$k-\epsilon$ RNG & 0.04 & 7.55 & 3.18 \\
$k-\omega$ SST low-Re & 0.98 & 7.66 & 3.73 \\
Transition-SST & 0.96 & 7.66 & 2.21 \\
\hline \multicolumn{4}{c}{ Hexagonal shaped bristle surrounding } \\
Turbulence & $e_{\text {rel,min }}[\%]$ & $e_{\text {rel,max }}[\%]$ & $\overline{e_{\text {rel }}}[\%]$ \\
model & 0.11 & 23.67 & 5.73 \\
\hline$k-\epsilon$ RNG & 0.31 & 23.03 & 4.85 \\
$k-\omega$ SST low- Re & 0.53 & 23.03 & 4.79 \\
Transition-SST & &
\end{tabular}

Table 4. Relative error $e_{r e l}$ of leakage mass flow rate $\dot{m}$ of variance $\sigma^{2}>0$ relating to regular arrangment with $\sigma^{2}=0$.

\begin{tabular}{lccc}
\hline \multicolumn{4}{c}{ Square shaped bristle surrounding } \\
$\sigma^{2}\left[\times 10^{-12}\right]$ & $e_{\text {rel,min }}[\%]$ & $e_{\text {rel,max }}[\%]$ & $\overline{e_{\text {rel }}[\%]}$ \\
\hline 1 & 0.05 & 0.52 & 0.27 \\
\hline \multicolumn{4}{c}{ Hexagonal shaped bristle surrounding } \\
$\sigma^{2}\left[\times 10^{-12}\right]$ & $e_{\text {rel,min }}[\%]$ & $e_{\text {rel,max }}[\%]$ & $\overline{e_{\text {rel }}[\%]}$ \\
\hline 1 & 0.12 & 2.95 & 0.89 \\
2 & 1.92 & 8.37 & 3.76 \\
\hline
\end{tabular}

is almost negligible, with this method phenomena observed in experiments can be reproduced numerically. As Braun et al. [6-8] have stated based on their experimental work, the flow within brush seals shows special flow patterns. Most notable are the rivering, jetting and lateral flow patterns. Rivering describes a fluid flow within a brush seal where, caused due to the non regular arrangement of the bristle pack, parts of the brush seal are partially or completely blocked for fluid flow due to contacting bristles. Therefore, in other sectors of the bristle pack enlarged flow channels emerge where a significantly larger mass flow rate passes by; the resulting flow pattern looks like a river winding through the bristle pack. Figure 10 shows an exemplary contour plot where this phenomena clearly can be observed. In addition the effects of jetting, partial accelerated fluid flow in regions of arising narrow gaps, also can be seen in figure 10. Lateral flow patterns primarily appear in simulations with square shaped bristle surroundings, wherein hexagonal ones this flow phenomena is prevented by the back tapering of the bristles.

\section{CONCLUSION}

In this study a CFD based leakage mass flow model for brush seals has been developed. Validating this model has shown that it is in accordance with experimental and numerical data 


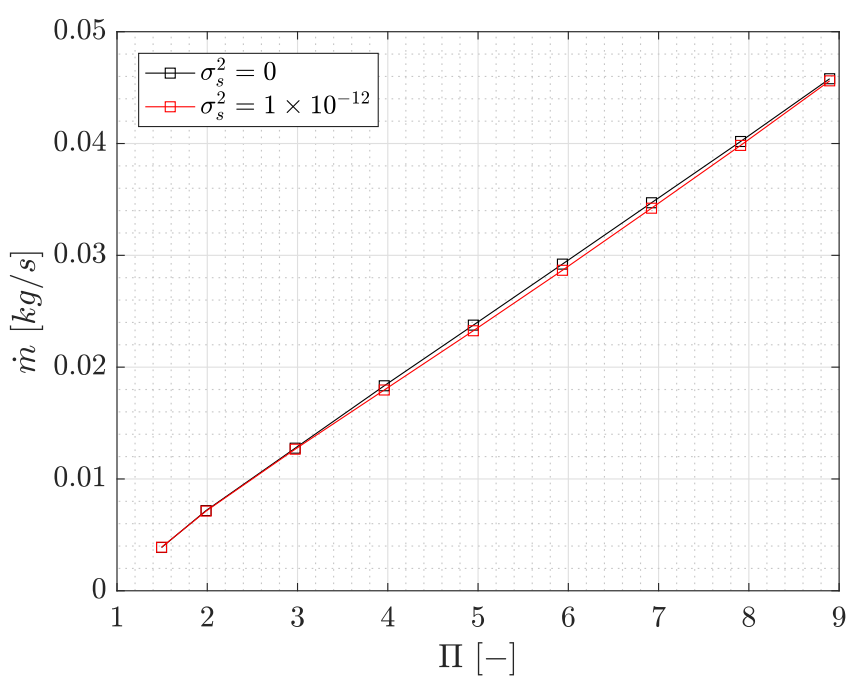

(a) Square shaped bristle surrounding.

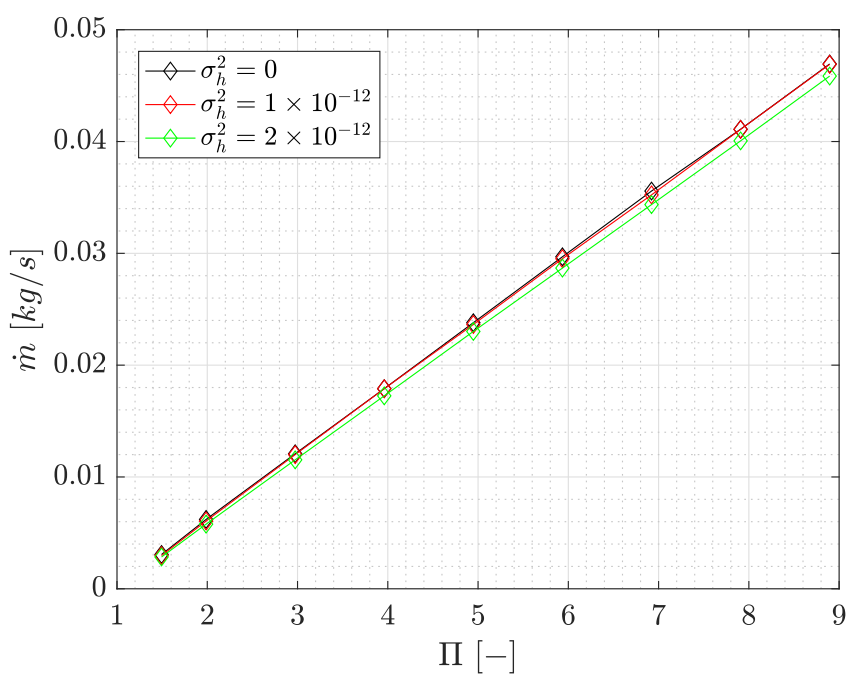

(b) Hexagonal shaped bristle surrounding.

Figure 9. Influence of quasi-chaotic displacement. For all results shown in this figure the Transition-SST model [47] for turbulence modeling, $\delta=8 \times 10^{-6} \mathrm{~m}$ and $N_{c}=4$ are used.

from multiple sources.

The influence of different geometrical and modeling parameters has been investigated, identifying the inter-bristle distance $\delta$ as the main leakage mass flow rate $\dot{m}$ affecting factor. Its representation of the narrowest gap transverse to the main flow path causes that $10 \%$ variation of this parameter results in a deviation of the leakage mass flow rate $\dot{m}$ from $15 \%$ up to $30 \%$.

Studying two differing arrangement setups, square and hexagonal shaped bristle surroundings, shows only a minor effect on the leakage mass flow rate $\dot{m}$. Nevertheless, the arrangement influences the observed flow patterns intensively. Furthermore, square shaped bristle surroundings perform better at low, hexagonal shaped circumscriptions better at high pressure ratios $\Pi$. For further work regarding the modeling of brush seals a hexagonal setup has been chosen, as that this setup represents the experimentally confirmed and more realistic composition.

To clarify the influence of turbulence modeling, the $k-\epsilon$ RNG model, the $k-\omega$ SST model with low-Reynolds correction, and the Transition-SST model have been tested against each other and experimental results. This analysis has proven the Transition-SST model to agree best with experimental results.

To consider realistic quasi-chaotic inner composition of a brush seal, a probability density function $P_{i}$ within the bristle surrounding shapes was implemented. Compared to a regular arrangement only minor deviations in the leakage mass flow rate $\dot{m}$ could be observed using this method. Due to the highly increased modeling effort required for this setup, its consideration in designing and evaluation of brush seals is appropriate when a in-depth analysis is aimed. Furthermore, with this approach experimentally observed flow phenomena like rivering, jetting, and lateral flow can be reproduced.

\section{ACKNOWLEDGMENTS}

This study was performed in cooperation with MTU Aero Engines. The support for this work by MTU Aero Engines and the permission to publish this paper and the containing data are highly acknowledged.

\section{REFERENCES}

[1] J. Munson and B. Steinetz. Specific fuel consumption and increased performance benefits possible with advanced seal technology. In 3 oth foint Propulsion Conference and Exhibit. American Institute of Aeronautics and Astronautics, June 1994.

[2] MTU Aero Engines AG. Brush seals - World class sealing technology, 2015.

[3] F. J. Bayley and C. A. Long. A combined experimental and theoretical study of flow and pressure distributions in a brush seal. In Volume 1: Turbomachinery. ASME, June 1992.

[4] A. T. O’Neill, S. I. Hogg, P. A. Withers, M. T. Turner, and T. V. Jones. Multiple brush seals in series. In Volume 3: Heat Transfer Electric Power Industrial and Cogeneration. ASME, June 1997.

[5] J. A. Carlile, R. C. Hendricks, and D. A. Yoder. Brush seal leakage performance with gaseous working fluids at static and low rotor speed conditions. In Volume 1: Turbomachinery. ASME, June 1992.

[6] M. J. Braun, R. C. Hendricks, and V. Canacci. Flow visualization in a simulated brush seal. In Volume 5: Manufacturing Materials and Metallurgy Ceramics Structures and Dynamics Controls, Diagnostics and Instrumentation General. ASME, June 1990.

[7] M. J. Braun, R. C. Hendricks, and V. A. Canacci. Non-intrusive qualitative and quantitative flow characterization and bulk flow model for brush seals. In International Tribology Conference, Nagoya, 1990.

[8] M. J. Braun, V. A. Canacci, and R. C. Hendricks. Flow visualization and quantitative velocity and pressure measurements in simulated single and double brush seals. Tribology Transactions, 34(1):70-80, January 1991.

[9] R. C. Hendricks, S. Schlumberger, M. J. Braun, F. Choy, and R. L. Mullen. A bulk flow model of a brush seal system. In Volume 1: Turbomachinery. ASME, June 1991.

[10] R. Hendricks, M. Proctor, S. Schlumberger, M. J. Braun, and R. L. Mullen. Some preliminary results of brush seal/rotor interference effects on leakage at zero and low rpm using a tapered-plug rotor. In 27 th foint Propulsion Conference. American Institute of Aeronautics and Astronautics, June 1991. 


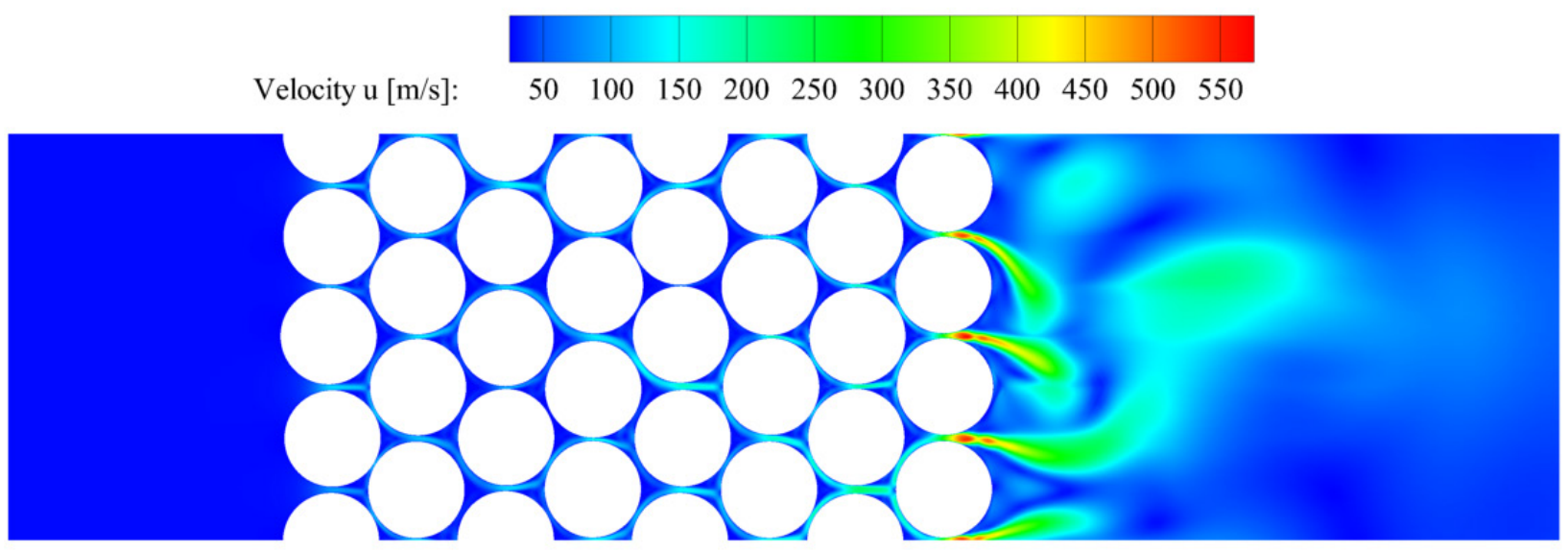

(a) Velocity field.

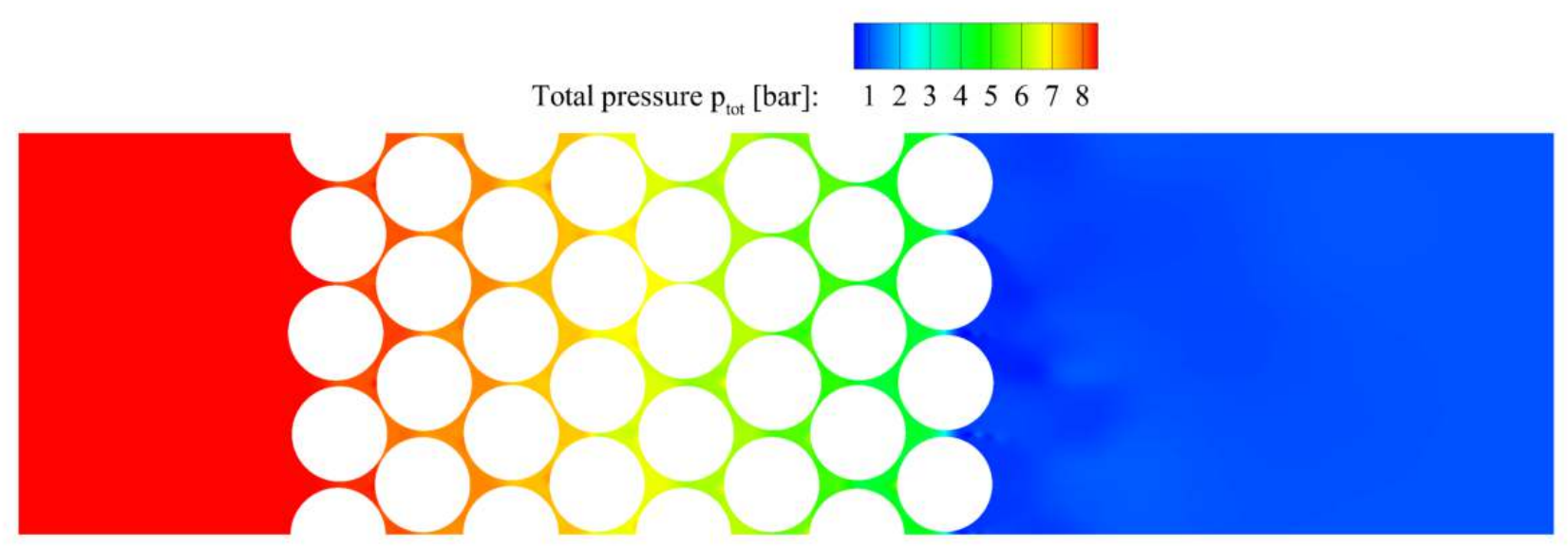

(b) Pressure field.

Figure 10. Exemplary contour plots of fluid flow domain for an quasi-chaotic arrangement with hexagonal bristle surrounding and a variance of $\sigma^{2}=0.2 \times 10^{-12}$, Transition-SST model [47] for turbulence modeling, an inter-bristle distance of $\delta=8 \times 10^{-6} \mathrm{~m}$, a pressure ratio of $\Pi=8.90$, and $N_{c}=4$.

[11] R. E. Chupp and C. Dowler. Simple leakage flow model for brush seals. In 27 th foint Propulsion Conference. American Institute of Aeronautics and Astronautics, June 1991.

[12] C. Dowler, R. E. Chupp, and G. F. Holle. Simple effective thickness model for circular brush seals. In 28th foint Propulsion Conference and Exhibit. American Institute of Aeronautics and Astronautics, July 1992.

[13] J. W. Chew, B. L. Lapworth, and P. J. Millener. Mathematical modeling of brush seals. International fournal of Heat and Fluid Flow, 16(6):493-500, December 1995.

[14] J. W. Chew and S. I. Hogg. Porosity modeling of brush seals. fournal of Tribology, 119(4):769, 1997.

[15] S. Pröstler. CFD modeling of brush seals. In European CFX Conference. ANSYS, September 2002.

[16] S. Pröstler. Modellierung und numerische Berechnungen von Wellenabdichtungen in Bürstenbauart. Verlag Dr. Hut, München, 2005.

[17] Y. Doğu and M. F. Aksit. Effects of geometry on brush seal pressure and flow fields-Part I: Front plate configurations. Fournal of Turbomachinery, 128(2):367, 2006.

[18] Y. Doğu and M. F. Aksit. Effects of geometry on brush seal pressure and flow fields-Part II: Backing plate configurations. Journal of Turbomachinery, 128(2):379, 2006.
[19] Y. Doğu, M. F. Aksit, M. Demiroglu, and O. S. Dinc. Evaluation of flow behavior for clearance brush seals. Fournal of Engineering for Gas Turbines and Power, 130(1):012507, 2008.

[20] Y. Doğu, M. C. Sertçakan, A. S. Bahar, A. Pişkin, E. Arıcan, and M. Kocagül. CFD investigation of brush seal leakage performance depending on geometric dimensions and operating conditions. In Volume ${ }_{5}$ C: Heat Transfer. ASME, June 2015.

[21] Y. Doğu, A. S. Bahar, M. C. Sertçakan, A. Pişkin, E. Arıcan, and M. Kocagül. Computational fluid dynamics investigation of brush seal leakage performance depending on geometric dimensions and operating conditions. Fournal of Engineering for Gas Turbines and Power, 138(3):032506, October 2015.

[22] L. H. Chen, P. E. Wood, T. V. Jones, and J. W. Chew. An iterative CFD and mechanical brush seal model and comparison with experimental results. Fournal of Engineering for Gas Turbines and Power, 121(4):656, 1999.

[23] L. H. Chen, P. E. Wood, T. V. Jones, and J. W. Chew. Detailed experimental studies of flow in large scale brush seal model and a comparison with CFD predictions. Journal of Engineering for Gas Turbines and Power, 122(4):672, 2000 
[24] M. Flouros, P. Hendrick, B. Outirba, F. Cottier, and S. Pröstler. Thermal and flow phenomena associated with the behavior of brush seals in aero engine bearing chambers. In Volume ${ }_{5} C$ : Heat Transfer. ASME, June 2014 .

[25] M. Flouros, P. Hendrick, B. Outirba, F. Cottier, and S. Pröstler. Thermal and flow phenomena associated with the behavior of brush seals in aero engine bearing chambers. Fournal of Engineering for Gas Turbines and Power, 137(9):092503, February 2015.

[26] B. Qiu and J. Li. Numerical investigations on the heat transfer behavior of brush seals using combined computational fluid dynamics and finite element method. Fournal of Heat Transfer, 135(12):122601, September 2013.

[27] B. Qiu, J. Li, and Z. Feng. Investigation of conjugate heat transfer in brush seals using porous media approach under local thermal nonequilibrium conditions. In Volume ${ }_{5}$ C: Heat Transfer. ASME, June 2015.

[28] J. Li, Y. Huang, Z. Li, Z. Feng, H. Yang, J. Yang, and L. Shi. Effects of clearances on the leakage flow characteristics of two kinds of brush seals and referenced labyrinth seal. In Volume 4: Heat Transfer, Parts A and B. ASME, 2010

[29] J. Li, B. Qiu, S. Jiang, X. Kong, and Z. Feng. Experimental and numerical investigations on the leakage flow characteristics of the labyrinth brush seal. In Volume 4: Heat Transfer, Parts A and B. ASME, June 2012.

[30] J. Li, B. Qiu, and Z. Feng. Experimental and numerical investigations on the leakage flow characteristics of the labyrinth brush seal. Fournal of Engineering for Gas Turbines and Power, 134(10):102509, 2012.

[31] P. Helm, A. Pugachev, and M. Neef. Breaking the swirl with brush seals: Numerical modeling and experimental evidence. In Volume 4 : Heat Transfer, Parts A and B. ASME, 2008.

[32] M. J. Braun and V. V. Kudriavtsev. A numerical simulation of a brush seal section and some experimental results. In Volume $3 \mathrm{C}$ : General. ASME, May 1993.

[33] M. J. Braun and V. V. Kudriavtsev. A numerical simulation of a brush seal section and some experimental results. Fournal of Turbomachinery, $117(1): 190,1995$

[34] V. V. Kudriavtsev and M. J. Braun. Model developments for the brush seal numerical simulation. fournal of Propulsion and Power, 12(1):193201, January 1996.

[35] R. C. Hendricks, V. V. Kudriavtsev, M. J. Braun, and M. M. Athavale. Flows in pinned arrays simulating brush seals. NASA Technical Memorandum, 1996.

[36] M. C. Sharatchandra and D. L. Rhode. Computed effects of rotorinduced swirl on brush seal performance-Part I: Leakage analysis. fournal of Tribology, 118(4):912, 1996.

[37] M. C. Sharatchandra and D. L. Rhode. Computed effects of rotorinduced swirl on brush seal performance-Part II: Bristle force analysis. Journal of Tribology, 118(4):920, 1996.

[38] D. Lelli, J. W. Chew, and P. Cooper. Combined 3 d fluid dynamics and mechanical modelling of brush seals. In Volume 3: Turbo Expo 2005, Parts $A$ and B. ASME, 2005.

[39] D. Lelli, J. W. Chew, and P. Cooper. Combined three-dimensional fluid dynamics and mechanical modeling of brush seals. Fournal of Turbomachinery, 128(1):188, 2006.

[40] M. J. Pekris, G. Franceschini, and D. R. H. Gillespie. Effect of geometric changes in an idealised contacting brush seal bristle pack on typical key performance measures. In Volume 5: Heat Transfer, Parts A and B. ASME, 2011

[41] M. J. Pekris, G. Franceschini, and D. R. H. Gillespie. An investigation of flow, mechanical and thermal performance of conventional and pressure-balanced brush seals. In Volume 4: Heat Transfer, Parts A and B. ASME, June 2012.

[42] M. J. Pekris, G. Franceschini, and D. R. H. Gillespie. An investigation of flow, mechanical, and thermal performance of conventional and pressure-balanced brush seals. Fournal of Engineering for Gas Turbines and Power, 136(6):062502, January 2014

[43] D. Sun, N.-N. Liu, C.-W. Fei, G.-Y. Hu, Y.-T. Ai, and Y.-S. Choy. Theoretical and numerical investigation on the leakage characteristics of brush seals based on fluid-structure interaction. Aerospace Science and Technology, 58:207-216, November 2016.
[44] J. W. Chew and C. Guardino. Simulation of flow and heat transfer in the tip region of a brush seal. International fournal of Heat and Fluid Flow, 25(4):649-658, August 2004

[45] S. Huang, S. Suo, Y. Li, and Y. Wang. Theoretical and experimental investigation on tip forces and temperature distributions of the brush seal coupled aerodynamic force. Journal of Engineering for Gas Turbines and Power, 136(5):052502, January 2014.

[46] I. B. Celik, U. Ghia, P. J. Roache, C. J. Freitas, H. Coleman, and P. E. Raad. Procedure for estimation and reporting of uncertainty due to discretization in CFD applications. Fournal of Fluids Engineering, 130(7):078001, 2008.

[47] F. R. Menter, R. B. Langtry, S. R. Likki, Y. B. Suzen, P. G. Huang, and S. Völker. A correlation-based transition model using local variables-Part I: Model formulation. Journal of Turbomachinery, 128(3):413, 2006.

[48] V. Yakhot and S. A. Orszag. Renormalization group analysis of turbulence. I. Basic theory. Fournal of Scientific Computing, 1(1):3-51, 1986.

[49] F. R. Menter. Zonal two equation k-w turbulence models for aerodynamic flows. In 23rd Fluid Dynamics, Plasmadynamics, and Lasers Conference. American Institute of Aeronautics and Astronautics, July 1993. 